\title{
VENTRICULOGRAFIA E MIELORADICULOGRAFIA COM CONTRASTES IODADOS HIDROSOLUVEIS
}

\author{
Ricardo REIXACH-GRANÉS * \\ Luiz Carlos G. Betting **
}

O estudo das formações do sistema nervoso central usando contraste remonta a 1918, quando Dandy ${ }^{6}$ introduziu a técnica da injeção de ar que continua a ser usada ainda hoje e que, embora seja o mais inócuo dos contrastes, apresenta dificuldades de interpretação, especialmente quando são pesquisadas as estruturas médias do encéfalo ou das porções inferiores do canal raqueano.

O Lipiodol introduzido como contraste positivo por Sicard e Forestier em 1922 e divulgado por Balado e Carrillo ${ }^{1}$, por longos anos foi considerado como o melhor procedimento para o estudo semiológico em neuroradiologia, embora com grandes inconvenientes pela dificuldade de sua retirada após o exame e também pelos quadros de aracnoidites e ventriculites, que eram as seqüências freqüentes após as explorações neuro-radiológicas.

Em 1950 Bull 4 introduziu o Pantopaque que tem maior fluidez sendo portanto, mais fácil sua retirada após o exame e menor índice de toxidade e de reação inflamatória, produzidas pelos resíduos de substância contrastante remanescente.

Os produtos hidrosolúveis e reabsorviveis foram experimentados a partir do Thorotrast (dióxido de tório), que permite boa visualização do sistema ventricular; porém a difusão do contraste no encéfalo produz graves complicações que obrigaram a abandoná-lo.

As radiculografias com iodeto de potássio e Abrodil (Raupp ${ }^{13}$ ) representam um novo avanço nas técnicas neuro-radiológicas, apresentando porém, os inconvenientes de dor intensa, a necessidade de raqui-anestesia, as crises hipotensivas graves e, muitas vezes, a deficiência de imagem contrastada, que não permite uma conclusão diagnóstica condizente com os inconvenientes.

O mono-iodo metano-sulfonato de sódio (Methiodal, Abrodil), embora conhecido desde 1931, não teve divulgação até 1946, segundo Caron e col. ${ }^{5}$,

Trabalho do Departamento de Neurologia e Neurocirurgia, do Hospital Regional da Santa Casa de Bauru (SP), apresentado no X Congresso Brasileiro de Neurocirurgia (Campinas, SP — julho de 1974): *Chefe do Departamento; ** Neurocirurgião assistente. 
sendo que as crises hipotensivas graves, as impotências funcionais das extremidades inferiores e sexuais prolongadas, parestesias persistentes ao longo de vários meses após o exame, embora representassem um avanço à semiologia radiológica do sistema nervoso, acabaram sendo abandonadas.

Heimburguer e col. ${ }^{8}$, em 1966, apresentaram o iotalamato de metilglucamina, como contraste hidrosolúvel reabsorvivel, sem os inconvenientes dos anteriores, e que nestes últimos anos, tem sido divulgado amplamente, tanto nas explorações ventriculares, como mielográficas ${ }^{2}, 3,5,7,9,10,11,12$, 15,16 .

Ultimamente, um novo ácido iodado, o ácido iocármico, tem sido utilizado para este tipo de exploração, apresentando menor toxidade e menos susceptibilidade de complicações que, embora exígüas, podia apresentar o iodo-metil-glucamina ${ }^{14}$.

\section{MATERIAL E MÉTODOS}

Há aproximadamente dois anos e meio estamos usando este tipo de contraste neuro-radiológico *, sendo nossa experiência baseada em 108 casos de mielografia lombar e 18 ventriculografias, sem observar qualquer complicação grave e com ótimos resultados quanto à visualização.
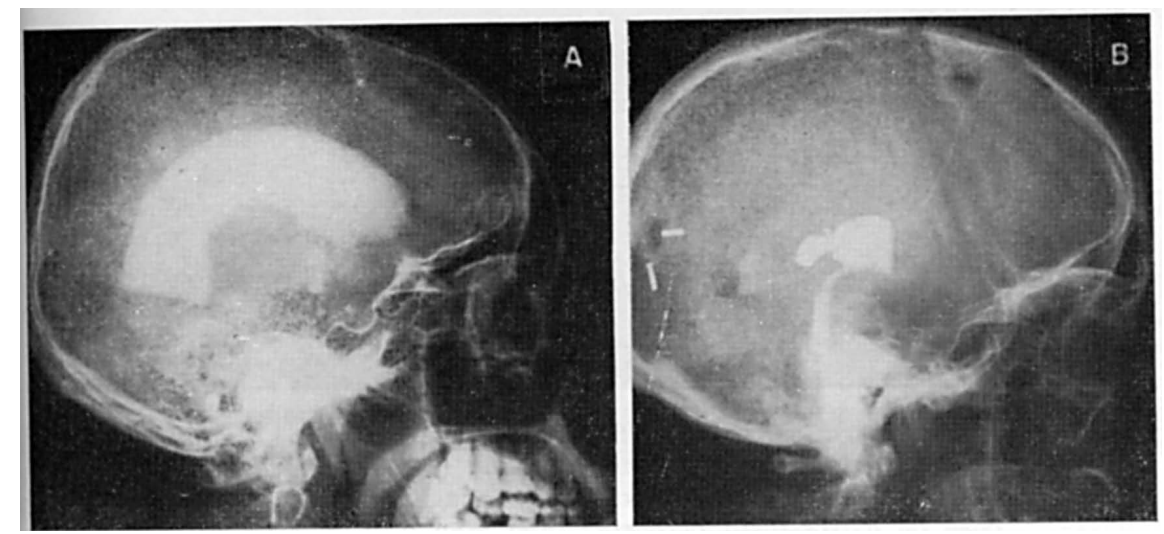

Fig. 1 - Ventriculografias com contraste hidrosolúvel: em A, bloqueio total do terceiro ventriculo por ependimoma intraventricular; em B, bloqueio total do aqueducto de Sylvius por cisticerco.

Na exploração ventriculográfica, procedemos ao preparo do paciente com Valium ou Inoval, e com anestesia geral, se for criança, efetuando-se com anestesia local a pequena trepanação frontal à direita.

* Contrix 28 e Sombril 60 (iotalamato de metilglucamina) e Dimer X (ácido iocármico) são os produtos comerciais por nós usados; o Conray 60, de composição quimica idêntica aos dois primeiros, não foi por nós usado. 

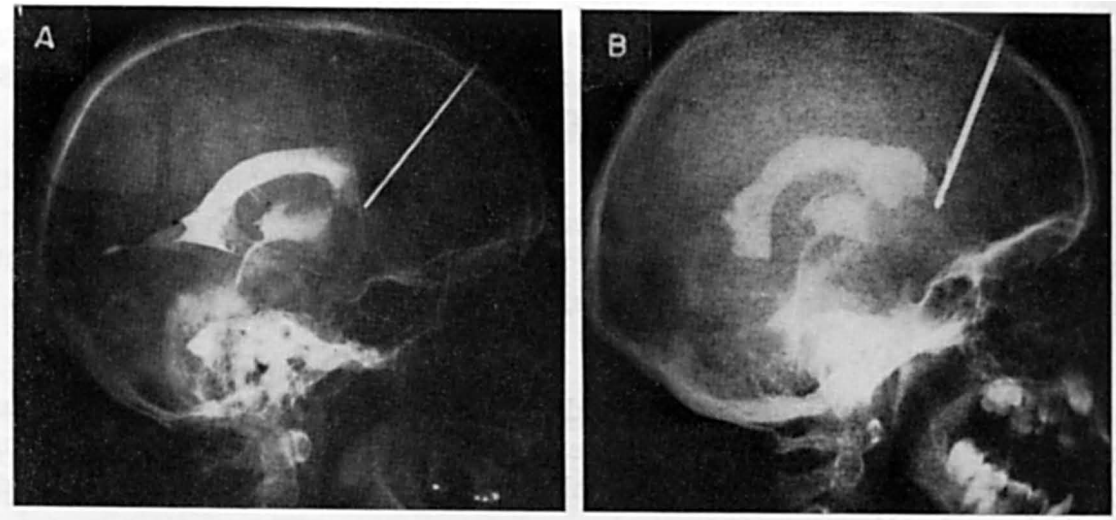

Fig. 2 - Ventriculografias com contraste hidrosolúvel: em A, estenose acentuada do aqueduto de Sylvius; em B, aspecto em um caso suspeito de hematoma na fossa posterior.
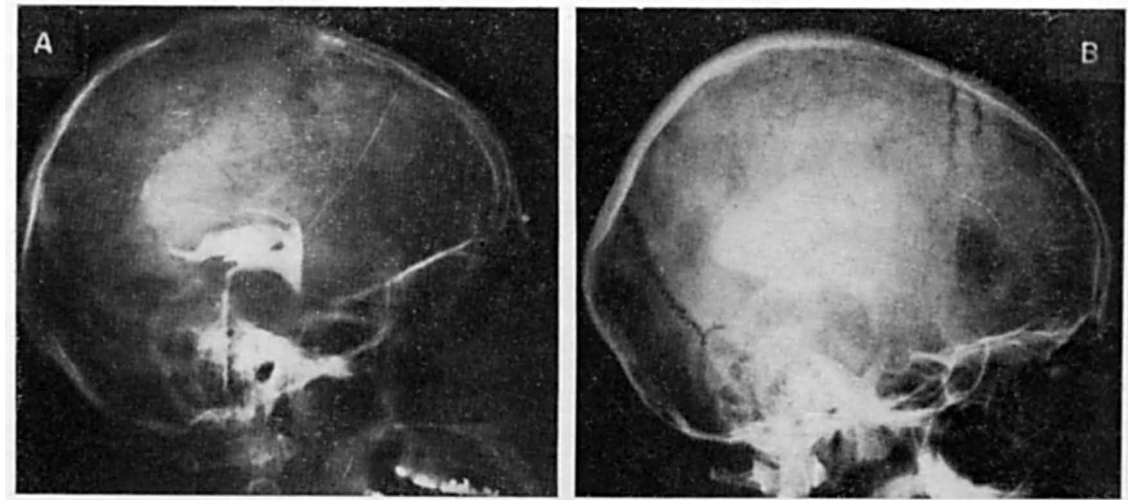

Fig 3 - Ventriculografias com contraste hidrosolúvel: em A, retificação $e$ deslocamento anterior do aqueduto de Sylvius em caso de tumor do cerebelo; em B, deslocamento superior do aqueduto de Sylvius em caso de astrocitoma cerebelar invadindo o IV ventrículo.

Inicialmente, introduziamos uma sonda flexivel no ventrículo e com controle pela TV, fazíamos a injeção do contraste; embora conseguíssemos acompanhar a progressão do contraste, as imagens radiográficas obtidas com os seriógrafos não apresentavam a nitidez desejada. Atualmente, após a punção ventricular e através da própria cânula metálica, injetamos o contraste, obtendo 4 ou 5 chapas radiográficas de perfil e umas 2 ou 3 em ântero-posterior para serem estudados e reinjetar nova quantidade de contraste se houver alguma dúvida.

No inicio, injetávamos 3 ou $4 \mathrm{ml}$ de contraste misturado com outros tantos de liquido cefalorraqueano (LCR). Ultimamente temos injetado 6 e $8 \mathrm{ml}$, sempre após aspirar uma quantidade de LCR que é misturada na própria seringa. 

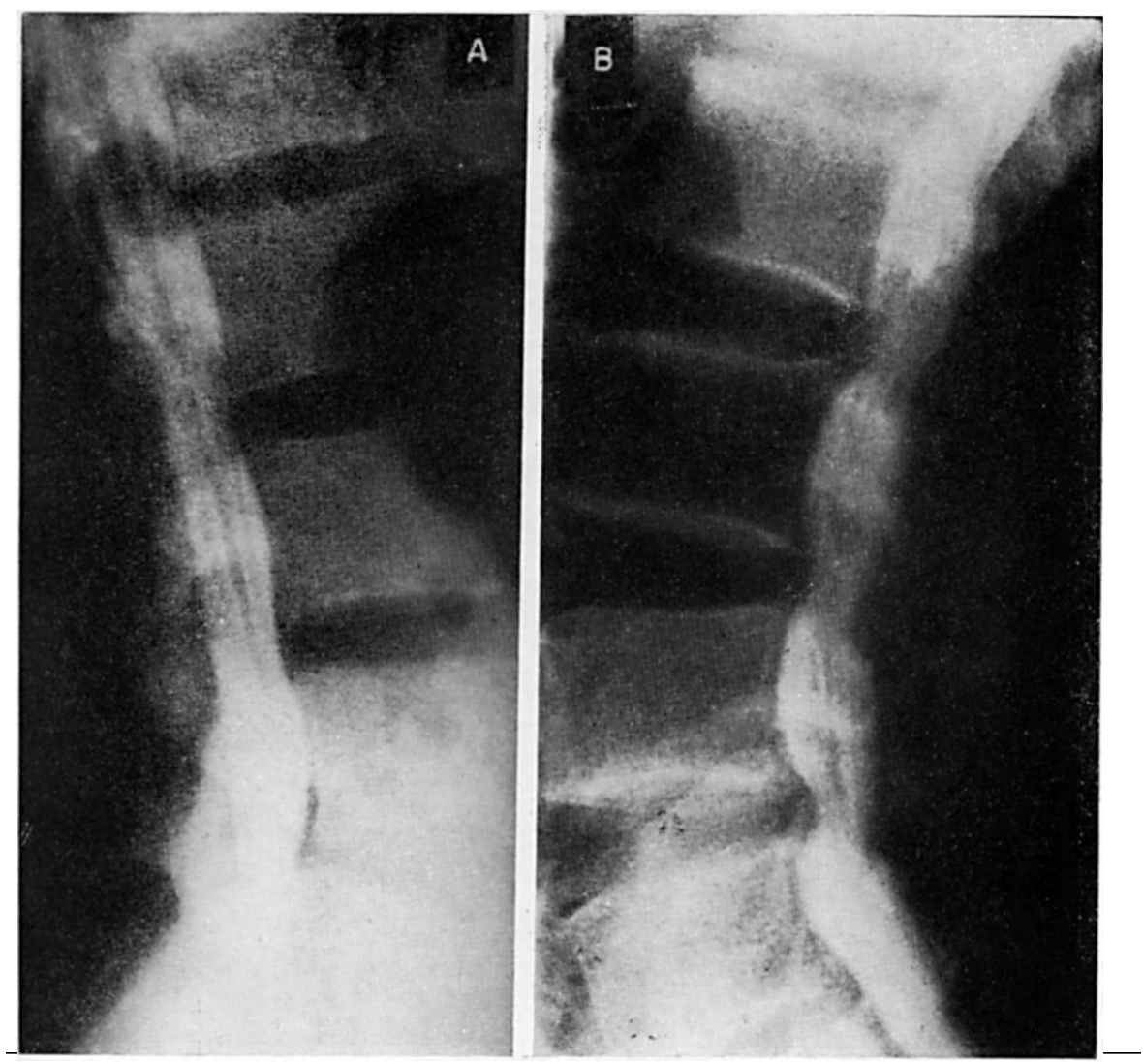

Fig. 4 - Mielografias com contraste hidrosolúvel: em $A$, discreta protrusão discal entre L3-L4 e L4-L5; em B, protrusöes discais múltiplas.

Continuamos usando a sonda flexivel ventricular nos casos de suspeita de ventriculos dilatados e naqueles em que deve ser melhor visibilizado 0 3. ventrículo; nestes casos procuramos colocar a ponta da sonda dentro do próprio ventriculo médio ou próximo do buraco de Monro.

Terminado o exame, o paciente é transportado para o quarto continuando em repouso por 24 horas, sendo administrada, por via muscular, nova dose de Diazepan, ou por venoclise em solução fisiológica, por duas ou três horas, após a ventriculografia.

No estudo mieloradiculográfico lombar procedemos sem qualquer medicação prévia para o doente que permanece sentado na mesa radiológica, sendo feita punção lombar ao nível L3-L4, retirando-se de 5 a $10 \mathrm{ml}$ de LCR para exame de rotina.

Seguros de estar dentro do espaço subaranóideo, procede-se com a seringa contendo já o contraste, que varia em torno de 5-6 $\mathrm{ml}$, e que é aspirado dentro da mesma seringa com uma quantidade igual de LCR, visando-se que se misture 

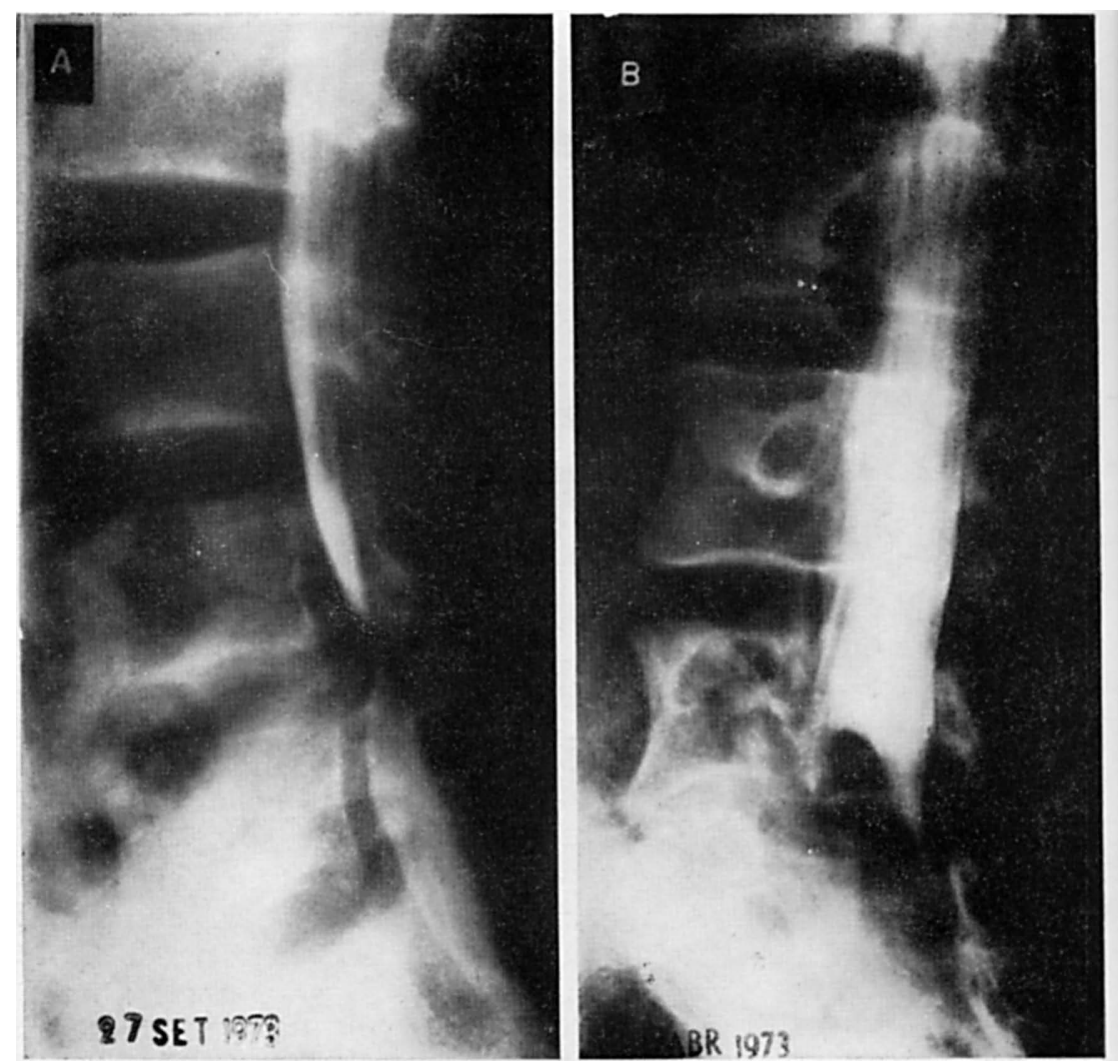

Fig. 5 - Mielografias com contraste hidrosolüvel: em $A$ e B, compressōes da cauda equina por tumores.

totalmente para ser reinjetado lentamente. Injetado o contraste o paciente é deitado na mesa radiológica, com ângulo de inclinação de mais de $45^{\circ}$ sendo, pelo controle televisionado, acompanhada de frente e de perfil, a posição do contraste. A seguir, mediante seriógrafo obtemos as chapas necessárias em posicão antero-posterior, em perfil, e, especialmente, em posição obliqua.

Sempre temos a preocupação de que o paciente fique em posição anti-Trendelemburg, a fim de que o contraste não se difunda no espaço ocupado pela medula.

Uma vez terminado o exame, o paciente é transportado em posição sentado para o quarto e nesta posição permanece por 8 a 10 horas.

E injetado Valium e Dipirona por via mscular, que é repetido algumas horas após, no caso do paciente queixar-se de algias nas extremidades ou na região lombar. No dia seguinte, passadas 24 horas do exame, o paicente passa a ter atividade normal, sendo dada alta se o exame for negativo. 


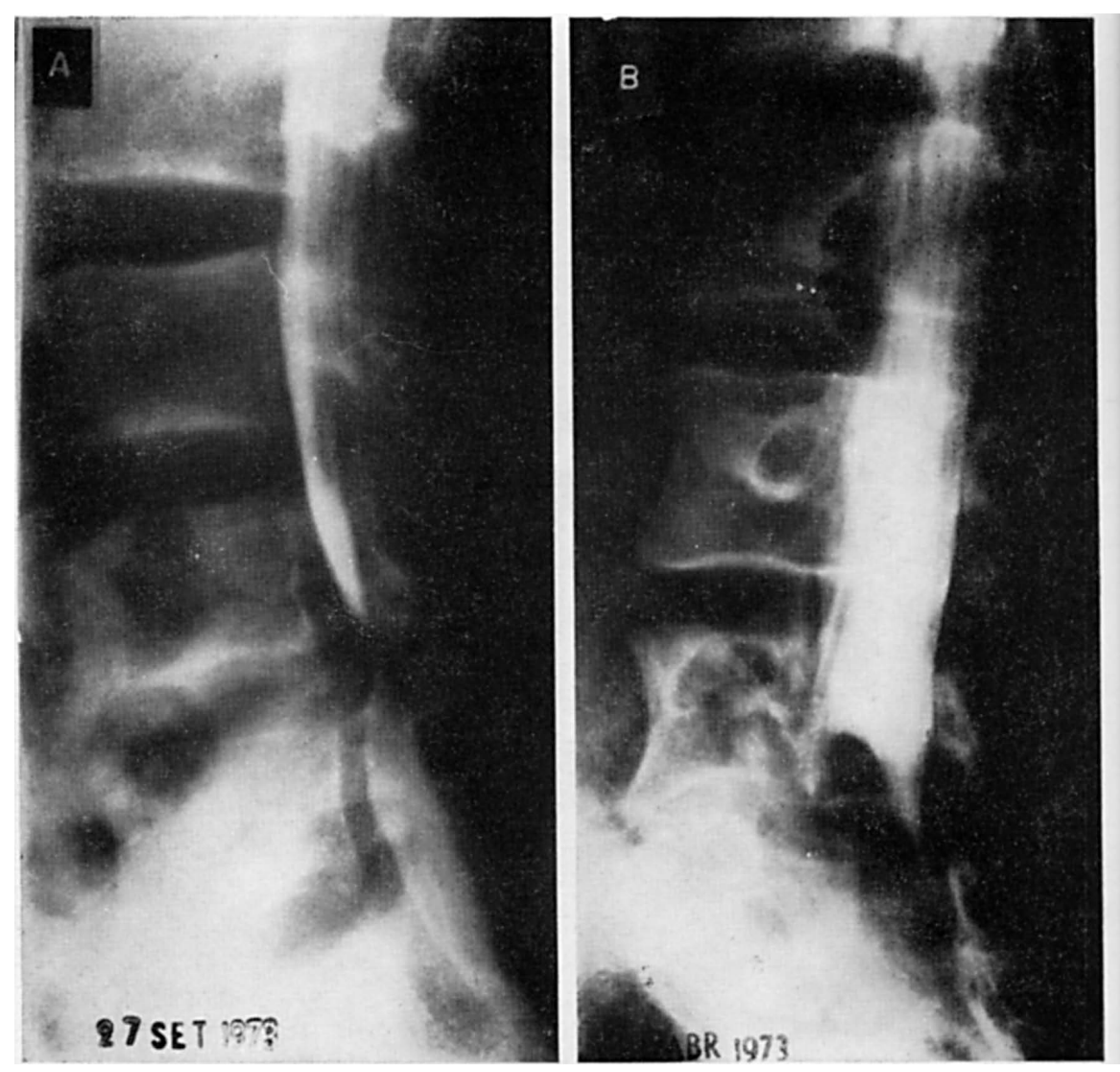

Fig. 6 - Mielografias com contraste hidrosolúvel: em A e B, hérnia discal em posições perfil e obliqua.

\section{COMENTARIOS}

O iotalamato de metilglucamina, usado como contraste vascular e renal, ao ser experimentado no espaço subaranóideo e ventricular revelou-se ser muito mais inócuo que os anteriores hidrosolúveis absorvíveis e, aperfeiçoando-se as técnicas de injeção e da posição do paciente, veio a resultar um agente bastante próximo do ideal. No início foi relatada a ocorrência, após o exame, de cãibras que, embora fugazes, determinavam em alguns pacientes 
desconforto e angústias indesejáveis. Isto tem sido corrigido com a precaução de misturar bem o contraste com igual quantidade de líquido cefalorraqueano, e ser injetado em forma lenta sempre em um nível inferior a L2. Deve-se igualmente manter a posição sentada do paciente durante um tempo sempre superior a 8 horas, lapso este considerado suficiente para que todo o contraste seja reabsorvido. A administração de Diazepan e de Dipirona, por via intramuscular, tem igualmente melhorado, para não dizer anulado esses inconvenientes.

$\mathrm{Na}$ nossa experiência de mieloradiculografias, temos observado poucos casos de cãibras passageiras, quando não foram observados com rigor a homogênea mistura do contraste, quando este tem sido em quantidade superior a $7 \mathrm{ml}$ e injetado com rapidez no canal subaranóideo. Caron ${ }^{5}$ refere que, logo depois de ter injetado o contraste, introduz dentro do espaço subaranóideo, $4 \mathrm{mg}$ de dexametasona ou hidrocortisona, a fim de evitar as possíveis cãibras pela irritação radicular.

Tem sido referido também o preparo da mistura do contraste em partes iguais com água bidestilada, antes de ser injetado no canal raqueano. Essa técnica, além de poder diminuir o poder irritativo do contraste, serve também para produzir uma mistura homogênea e evitar a possível distorção da imagem contrastada, que daria lacunas nas placas radiográficas e poderiam confundir-se com imagens patológicas o que nós não temos observado em nossos exames.

Caron ${ }^{5}$ refere que, em três casos, o contraste foi injetado no espaço epidural e que teria provocado intensa reação nos pacientes. Na nossa casuística, em um único caso foi injetado contraste no espaço epidural com ascensão rápida para a região torácica. O paciente sentiu intensa dor pré-cordial e cãibras abdominais, seguidos de palidez acentuada e náuseas, com discreta hipotensão arterial. A administração de dipirona e $4 \mathrm{mg}$ de dexametazona foram suficientes para sustar completamente e em pouco tempo, essas sensações desagrađáveis e o paciente, três horas depois, estava totalmente livre dos sintomas. Outro caso de cãibras violentas foi por bloqueio acentuado do espaço ao nível de L4-L5, com a ascensão do contraste para niveis mais altos. Nesses casos com suspeita do processo obstrutivo é aconselhável o controle televisionado diminuindo a quantidade de contraste que será injetada com maior precaução. Nos casos em que usamos o ácido iocármico (Dimer $\mathrm{X}$ ) não temos observado qualquer reação, ainda que ligeira, confirmando também as vantagens deste último contraste.

Quando, nas explorações do canal raqueano, devem ser visadas porções mais altas, torácicas ou cervicais e, inclusive para o estudo do ângulo ponto-cerebelar, excluimos os contrastes hidrosolúveis e damos preferência ao Duroliopaque (mono-iodo-esterato de etilo) contraste liposolúvel ultra-fluído e que é retirado com facilidade do fundo do saco dural sendo que não é irritante, e o remanescente que ficar em pouca quantidade, é reabsorvido totalmente em algumas semanas. 
Nas ventriculografias feitas sob o écran televisionado, embora fosse possivel acompanhar com maior facilidade o progresso do contraste, não conseguíamos clichês com a nitidez desejada e também, inicialmente, por precaução, injetávamos quantidade de contrastes que não ultrapassavam a $3 \mathrm{ml}$. Atualmente, no craniógrafo e sem o recurso de TV, pode-se obter imagens de grande nitidez, acompanhando-se perfeitamente a passagem do contraste pelas cavidades ventriculares até a cisterna magna.

Não temos tido qualquer complicação em nossos exames. Num único paciente, por deficiência técnica, o contraste (Dimer $\mathrm{X}$ ) extravasou do ventrículo e difundiu-se pelo espaço subaracnóideo do hemisfério, sem contudo provocar qualquer problema. $O$ fato de ter sempre a presença do anestesista e com venoclise de Diazepan afasta também as possibilidades de ter obscrvado crises convulsivas.

Pode-se concluir dizendo que estes novos contrastes hidrosolúveis reabsorvíveis, bastante inócuos e sem complicações severas, apresentam um considerável progresso nas explorações neuro-radiológicas para visualizar as formações medianas do encéfalo, cuja patologia é complexa.

Por outro lado, o contingente de ciáticas que se apresenta constantemente nos consultórios neurológicos, podem agora a nosso ver serem resolvidos com facilidade, sem os inconvenientes e sequelas que os produtos anteriores produziam com grande freqüência, tornando cauteloso o seu uso.

\section{RESUMO}

Com base em casuistica de 136 exames neuro-radiológicos (ventriculografias e mieloradiculografias) utilizando contrastes hidrosolúveis reabsorvíveis (iotalamato de metilglucamina e ácido iocármico), os autores ressaltam as vantagens destes produtos que permitem sem maiores complicações, perfeita visualização das estruturas examinadas.

SUMMARY

Ventriculogruphy und myeloradiculogruphy with water-soluble contrast

A casuistic of 136 neuro-radiologics examinations (ventriculographies and myeloradiculcgraphies) using water soluble contrasts (Metilglucamine iotalamate and Iocarmic acid) is reported. The authors call attention for the advantages of these products that get, without any major problems, the perfect visualization of the researched structures.

\section{REFERENCIAS}

1. BALADO, M. \& CARRILlo, R. - Estudio comparativo de los metodos modernos de diagnóstico neuroquirúrgico. Resultados de la ventriculografiá com lipidol. Semana Médica (Buenos Aires) 10:717, 1935. 
2. BALAPARAMESWARARAO, S.; DINAKAR, I. \& PUllaREdDY, C. - Conray myelography - Conray ventriculography. Excerpta Médica, International Congress Series, 293:204, 1973.

3. BENITO, C. \& ESCAPA, V. G. - Nueva técnica y contraste en radiculografia. Radiologia 67:3, 1969.

4. BULL, J. W. B. - Positive contrast ventriculography. Acta Radiol. 34:253, 1950.

5. CARON, J.; ReINIER, J. C.; BREGEON, C. \& CARON-POITREAU, G. - Premiers essals de radiculographie lombo-sacrée a l'lothalamate de méthyl-glucamine. J. Radiol. et D'Electtrol. 50:157, 1969.

6. DANDY, W. E. - Ventriculography following the injection of air into the cerebral ventricles. Ann. Surg. 68:5, 1918.

7. GONSETTE, R. - Positive ventriculography and myelography with recent water-soluble contrast media. Excepta Médica, International Congress Series, 293:108, 1973.

8. HEIMBURGER, R. F.; KALSBECK, J. E.; CAMPBELL, R. L. \& MEALEY Jr., J. - Positive contrast cerebral ventriculography using water-soluble media. J. Neurol. Neurosurg. Psychiat. 29:281, 1966.

9. ISAMAT, F.; MIRANDA, A. M. \& BARTUMEUS, F. - Ventriculo-sériographie cér;brale avec contraste positif hydrosoluble. Neuro-Chirurgie (Paris) 16:577, 1970.

10. NOVAES, V.; SEBBA, O. \& CAMPOS, J. - Ventriculografia com contraste hidrosolúvel. Arq. Neuro-Psiquiat. (São Paulo) 30:111, 1972.

11. PICAZA, J. A.; HUNTER, S. E. \& LEE, L. - Seizures associated with the use of meglumine iothalamate $60 \%$ in ventriculography. J. Neurosurg. 36:4, 1972.

12. RAIMONDI, J. A.; SAMUELSON, G. H. \& YASAGaray, L. - Positive contrast (Conray 60) serial ventriculography in the normal and hydrocephalic infant. Ann. Radiol. 12:377, 1969.

13. RAUPP, S. - Radiculografia com contraste hidrosolúvel, Tese de Doutoramento. Universidade do Rio Grande do Sul, Porto Alegre, 1960.

14. TADMOR, R.; KOSARY, I. Z.; OUKNINE, G. \& BRAHAM, J. - Lumbosacral myelography with Dimer X: report of 100 cases. J. Neurosurg. 39:3, 1973.

15. VALLATI, G.; MULLAN, S. \& DOBBEN, G. - Ventriculografia cerebrale e mielografia mediante un nuovo mezzo di contrasto idrosolubile e riassorbibile. Minerva Neurochir. 9:186, 1965.

16. YAMADA, Y.; HIROSHI, H. \& TAJIMA, M. - Conray ventriculography in the diagnostic of infantile hydrocephalus: technical note. J. Neurosurg. 39:63, 1973.

Clinica Neurologica - Hospital Regional da Santa Casa - 17100 Bauru, SP - Brasil. 